Estudios Constitucionales, Año 16, № 2, 2018, pp. 117-140

ISSN 07180195

Centro de Estudios Constitucionales de Chile Universidad de Talca

"Obergefell y el largo camino hacia el matrimonio igualitario"

Pedro S. Guerra Araya

\title{
OBERGEFELL Y EL LARGO CAMINO HACIA EL MATRIMONIO IGUALITARIO*
}

\author{
OBERGEFELL AND THE LONG ROAD TOWARDS EQUAL MARRIAGE
}

\author{
Pedro S. Guerra Araya ${ }^{* *}$ \\ Universidad de Valparaíso \\ psguerra76@gmail.com
}

RESUMEN: El objetivo de este articulo es examinar los aspectos más relevantes de la sentencia dictada en 2015 por el Tribunal Supremo de los Estados Unidos de América en el caso Obergefell et al. v. Hodges, y la forma en que los argumentos que los sentenciadores de mayoría desarrollaron podrían iluminar la discusión sobre el matrimonio entre personas del mismo sexo en nuestro pais. Así, se procurará determinar qué anclajes constitucionales identificaron los jueces en su sentencia, y la forma en que esta se hace cargo de re-interpretar el ordenamiento constitucional a partir de la evolución que una institución como el matrimonio ha experimentado y de la necesidad de igualar a las minorías sexuales en ese ámbito.

ABSTRACT: The aim of this article is to examine the most relevant aspects of the decision delivered in 2015 by the Supreme Court of the United States of America in the case know as Obergefell et al. $v$. Hodges, and the way the majority opinion could shed a light on the discussion on same-sex marriage in our country. Thus, we will try to determine which constitutional anchors the judges identified in their sentence, and the way in which it is responsible for re-interpreting the constitutional order based on the evolution that an institution such as marriage has experienced and the need to make sexual minorities equal in that area.

Palabras Clave: Matrimonio Igualitario. Obergefell v. Hodges. Matrimonio Homosexual. Igualdad ante la Ley.

KEY WORDS: Equal Marriage. Obergefell v. Hodges. Gay Marriage. Equality before the Law.

\section{INTRODUCCIÓN}

Hace tres años, y estando aún con vida Antonin Scalia, el mundo progresista recibió con alegría la decisión de la Corte Suprema de los Estados Unidos de

\footnotetext{
* Trabajo recibido el 21 de marzo de 2017 y aprobado el 18 de abril de 2018.

** Licenciado en Ciencias Jurídicas, Pontificia Universidad Católica de Valparaíso, Chile. Abogado. Magíster en Políticas Públicas y Sociales, Universidad Pompeu Fabra, Barcelona, España. Estudiante del Programa de Doctorado en Derecho, Universidad de Valparaíso. Correo electrónico psguerra76@gmail.com. El autor agradece los comentarios y sugerencias de los profesores Luis Villavicencio y Pietro Sferrazza, ambos de la Escuela de Derecho de la Universidad de Valparaíso.
} 
América -en adelante la Corte- de otorgar plena validez al matrimonio entre personas del mismo sexo a lo largo y ancho de los estados que conforman la Unión. La decisión del caso, que se conocería como Obergefell v. Hodges ${ }^{1}$ o simplemente Obergefell -como se denominará en las páginas que siguen- vendría a ser, como muchas otras piezas de jurisprudencia norteamericana, la síntesis de largas y complejas luchas sociales que desde hace mucho vienen empujando a una sociedad en gran medida puritana y conservadora hacia una mayor integración de minorías. Miles de personas, homo y heterosexuales, pintarían sus redes sociales con los colores de la bandera gay y el escritor David Sedaris, publicaría un humorístico artículo, relatando como había recibido la decisión de la Corte en su iPad mientras paseaba a su perro y recogía basura por su barrio, reflexionando sobre como en su juventud ser gay en Raleigh, Carolina del Norte, era lo peor que podría haberle ocurrido a una persona ${ }^{2}$.

Obergefell es una de las piezas de jurisprudencia más significativas que la Corte ha generado y da cuenta de un debate largo y enconado entre los detractores del matrimonio igualitario y sus sostenedores. Como sostendrá Clare Huntington "El debate sobre el matrimonio igualitario fue fundamentalmente sobre el control del significado -la fachada social- del matrimonio"3-4. En el debate confluyen fundamentalmente distintas ideas sobre la forma de la familia y sobre si la Constitución debe amparar y hacerse cargo de modelaciones que no existían en tiempos de los padres fundadores, así como si es o no legítimo privar a una minoría de aquello que sí se concede a una mayoría.

En este artículo se presentará un análisis de los antecedentes del caso y de los argumentos que los jueces de la Corte desarrollaron en su sentencia de 2015 para ampliar el espectro de cobertura del matrimonio igualitario a todos los estados de la Unión, para culminar con una reflexión respecto del debate nacional sobre una modificación de la institución del matrimonio. En primer lugar, se

\footnotetext{
1 Supreme Court of Justice, 576 U.S. (2015) 26 de junio de 2015.

2 Sedaris (2015).

3 Huntington (2015), p. 25

4 En un sentido curiosamente similar, pero con diferente animosidad, sostiene Hernán Corral que la lucha por el matrimonio igualitario es más bien la búsqueda de una legitimación de un estilo de vida y una práctica homosexual. "Diríase que no es el matrimonio que realmente desean los integrantes del movimiento gay, sino su prestigio y su carga simbólica de justificación y honra de una forma deseable socialmente de ejercicio de la sexualidad”. Corral (2013), p. 106.
} 
dará cuenta del caso que dio origen a la decisión jurisprudencial; se explorarán, en segundo lugar, los argumentos que sostienen la decisión, y, en tercer lugar, se explorará el estado actual de la discusión en nuestro país y las perspectivas de futuro y posibles escollos que una reforma podría enfrentar.

\section{EL CASO EN DISPUTA}

\section{James Obergefell}

Los héroes de los derechos civiles son personajes improbables: nadie podría afirmar exactamente desde dónde salen y qué motivos los llevan a enarbolar qué banderas. Su fisonomía y su temple no pueden sino ser coherentes con los tiempos que viven y las causas que representan. En ese contexto James Obergefell en EE.UU. es un símbolo improbable, accidental, pero representativo de los nuevos cursos que las luchas de derechos civiles han tomado en el mundo.

James Obergefell nació en algún punto no establecido de la década del sesenta, en Ohio y en el seno de una familia católica. Se reveló como gay a sus veinte años y a mediados de los años noventa, conoció a quien sería su pareja, John Arthur, con quien formaría una familia -en el amplio sentido de la palabra familia- y con quien viviría hasta su muerte, en 2013. La enfermedad de John, una esclerosis lateral amiotrófica, desataría dos años después el fallo judicial que aquí se comenta. Sabiendo John que moriría en el corto plazo, la pareja decidió contraer matrimonio. Dado que las leyes del estado de Ohio no permitían a las parejas del mismo sexo contraer matrimonio y con John en un estado de casi inmovilidad, la pareja viajó al estado de Maryland para casarse ${ }^{5}$. John Arthur moriría tres meses después, a consecuencia de las complicaciones de su enfermedad. Su marido solicitó al estado de su residencia el reconocimiento de su calidad de cónyuge sobreviviente en el certificado de defunción de John: el estado de Ohio, al denegarlo a través de su Departamento de Salud, sería el objeto de la acción que culminaría en 2015 con el pronunciamiento de los jueces de la Corte Suprema, en el caso que se conoció como Obergefell et al. v. Hodges, Director, Ohio Department of Health.

\footnotetext{
5 La pareja viajó en un vuelo especial financiado por un grupo de amigos: John Arthur y James Obergefell se casaron en el avión estacionado sobre el asfalto del aeropuerto de Maryland, ante la imposibilidad de que John pudiera bajar de la aeronave, y bajo los oficios civiles de Paulette Roberts, tía de uno de los novios.
} 


\section{OBERGEFELL y SUS PRECEDENTES}

Si bien a primera vista pareciera que Obergefell es una gema solitaria en la larga lista de decisiones de la Corte que se pueden clasificar bajo la etiqueta temática de "derechos civiles", una mirada en profundidad mostrará que el fallo de 2015 viene a ser el desenlace de un proceso de cambio jurisprudencial que tiene sus raíces en profundos cambios culturales y demográficos que han sido a su vez recepcionados por el máximo tribunal. En esto, que se conoce como concretización constitucional, es fundamental el proceso interpretativo que la Corte realiza cuando, en ausencia de un contenido claro, éste es determinado mediante una incorporación de la realidad que se trata de regular ${ }^{6}$.

En ese sentido, una larga serie de decisiones jurisprudenciales claves que se han venido produciendo desde hace unos años, han ido preparando el terreno para la decisión de Obergefell, generando argumentos, de mayoría o disenso, que la alimentan en uno u otro sentido. Estos son consecuencia de concepciones cada vez más amplias de familia, que han ocasionado sentidas derrotas al mundo conservador en el terreno de los derechos de las minorías sexuales. No obstante esta evolución puede aún sufrir retrocesos, lo cierto es que Obergefell demuestra una tendencia clara y despliega además un efecto mediático relevante y geográficamente extenso. Se trata de un punto de inflexión en el reconocimiento a nivel federal del matrimonio de las parejas del mismo sexo. Y, por supuesto, de una fuente inspiradora para el desarrollo que el problema pueda tener en otras latitudes.

Es posible así identificar ciertas piezas de jurisprudencia que, ya sea por la lógica del razonamiento interpretativo de determinadas garantías constitucionales como por abordar derechamente conflictos relativos al matrimonio y a las minorías sexuales, han ido abonando el terreno para una decisión de la magnitud y espectro de Obergefell. Kenji Yoshino efectúa una interesante exposición de los mecanismos a través de los cuales Obergefell ha logrado justificar una ampliación del derecho al matrimonio y, en el camino, establecer nuevos derechos no originalmente contemplados en la Constitución americana ${ }^{7}$.

Así es posible citar a Loving v. Virginia ${ }^{8}$, que en 1967 quebró la prohibición de matrimonios interraciales por vulnerar tanto la cláusula del debido proceso

6 Hesse (1992), p. 43.

7 Yoshino (2015), pp. 147-179.

8 Supreme Court of Justice, 388 U.S. 1_ (1967), 12 de junio de 1967. 
como de la igual protección ante la ley, ambas contenidas como se verá en la Decimocuarta Enmienda de la Constitución. En 2003, en la decisión Lawrence v. Texas $^{9}$, la Corte consideró inconstitucionales las normas de Texas y varios otros estados en que se penalizaba la sodomía, dando por terminado el imperio que se había inaugurado en 1986 con Bowers v. Hardwick, donde no se reconoció el derecho de las personas a mantener relaciones homosexuales. Pero quizás el antecedente más directo de Obergefell sea la decisión en Windsor v. United States ${ }^{10}$ en que la Corte declaró la inconstitucionalidad de la Ley de Defensa del Matrimonio o Defense of Marriage Act (DOMA) ${ }^{11}$ basándose en que ésta infringía la garantía del debido proceso en sus definiciones de matrimonio y de cónyuge.

Como señalan Blackman y Wasserman, la historia de Edith Windsor ${ }^{12}$ desató, a partir de junio de 2013 "una masiva campaña de litigios constitucionales paralelos, desafiando idénticas prohibiciones de matrimonio entre parejas del mismo sexo, en treinta y siete estados y dos territorios, cubriendo nueve circuitos federales"13-14.

9 Supreme Court of Justice, 539 U.S. 558 (2003), 26 de junio de 2003.

10 Supreme Court of Justice, 570 U.S._ (2013), 26 de junio de 2013.

11 Como refiere Martel la Defense of Marriage Act, de 1996, limitó a nivel federal la definición del matrimonio a un hombre y una mujer, no obligando a los estados a reconocer un matrimonio entre personas del mismo sexo celebrado en otro. La ley fue aprobada con votos republicanos, sin la oposición -veto- del presidente demócrata Bill Clinton. MARTEL (2013).

12 La demandante, casada y viuda de Thea Spye en Canadá libró una batalla judicial para que su matrimonio fuera reconocido en la jurisdicción de Nueva York, con la consecuente rebaja impositiva de más de trescientos mil dólares para la cónyuge heredera. El problema que se plantea la Corte de Windsor es en principio sobre competencias superpuestas entre el nivel estatal y el federal. La DOMA pretende estatuir una forma de matrimonio a nivel federal, mientras que la legislación del estado de Nueva York (donde residía Edith Windsor) permitía que dos personas del mismo sexo se casaran. Es ahí donde aparece el nivel de discusión sobre civil rights: Para la Corte de Windsor se hace necesario analizar la validez de la intervención federal, mediante la DOMA, en un ámbito de autoridad propio de los estados. Mientras la legislación del estado de Nueva York le otorgaba un estatus de consideración al matrimonio entre dos personas del mismo sexo, la legislación federal la negaba, produciéndose un atentado contra la Quinta Enmienda Constitucional, es decir en contra de las libertades.

13 Blackman y Wasserman (2016), p. 247.

14 Resulta interesante notar como la decisión de Windsor en 2013 y la de Obergefell en 2015 aceleraron de forma notoria la celebración de matrimonios entre personas del mismo sexo. Los datos y cifras muestran una proporción cada vez mayor de las parejas del mismo sexo a casarse. GaTES, G. J.; Brown, T. N. T. (2015). 
De esta forma, tanto Windsor como Obergefell y todos los demás casos que motivaron las decisiones, corresponden a un mismo esquema de conflicto. Se trataba de desafiar a estados que no reconocían el matrimonio entre personas del mismo sexo y en que o bien se negaban licencias para contraer matrimonio o bien no se otorgaba reconocimiento a los matrimonios que se habían celebrado en otros. Si bien los casos centrales son aquellos que tuvieron un camino hacia la Corte Suprema, no es menos cierto que una profusa litigiosidad a nivel estatal creó un ambiente social y judicial proclive al reconocimiento federal que se produce finalmente con Obergefell15-16.

\section{LA SENTENCIA}

\section{COMENTARios PREVIOS}

Como muchas otras decisiones controvertidas, Obergefell es una decisión de mayoría pero en ningún caso de unanimidad. Fue decidida por cinco votos a favor -Justices Ginsburg, Breyer, Sotomayor, Kagan y Kennedy, este último como redactor de la sentencia- y cuatro en contra -Roberts, Juez Presidente del Tribunal, Thomas, Scalia y Alito ${ }^{17}$. La cuestión central que se somete a

$15 \mathrm{Al}$ respecto Blackman y Wasserman explican el funcionamiento de los precedentes en el sistema americano. Si bien una sentencia judicial tiene lo que en Chile llamamos el "efectos relativo de las sentencias", y solo resulta en consecuencia vinculante para las partes que litigaron en ella, estas pueden tener un efecto cuando son alegadas como precedente en un litigio posterior. Cada litigante que quiera aprovechar en su favor una decisión judicial deberá hacer valer dicho precedente en un nuevo litigio. Cuando esto logra escalar el entramado jerárquico de los Tribunales y llegar a la Corte Suprema, se produce una decisión que crea un precedente potencialmente aplicable en todos los estados de la Unión. BLACKMAN y WASSERMAN (2016), pp. 250-251. En ese sentido es interesante destacar que el proceso interpretativo, en un determinado sentido, se va construyendo desde abajo hacia arriba, para finalmente abarcar a todo el país. Eso implica que para llegar a una decisión como Obergefell, ha habido una serie de pasos previos, llamémoslos de ensayos y error, de las interpretaciones de las cuales se hará finalmente cargo la sentencia.

16 Como documentan Cecilia Grossman y Marisa Herrara, en el caso argentino y previo a la dictación de la Ley No 26.618 que permitió el matrimonio igualitario, la constitucionalidad del artículo 172 del Código Civil -equivalente en términos de exigencia de diferente sexo, a nuestro artículo 102- fue puesta en cuestión en varias ocasiones, en distintos niveles de jurisdicción y con distintos resultados. GrossmaN y Herrera (2013).

17 Los jueces concurrentes a la opinión mayoritaria han sido nominados respectivamente por los gobiernos de Bill Clinton (Ginsburg y Breyer), Barak Obama (Kagan y Sotomayor) y Ronald Reagan (Kennedy). Los jueces disidentes lo han sido por George W. Bush (Alito), Ronald Reagan (Scalia), George H. Bush (Thomas) y George W. Bush (Roberts, Juez Presidente del Tribunal). Como se ve en los nombramientos de los jueces concurrentes a la decisión han intervenido tanto gobiernos de signo republicano como de- 
conocimiento de la Corte es el problema de la realización de la libertad que la Constitución otorga a todos quienes están bajo su imperio, a través del derecho a contraer matrimonio con alguien del mismo sexo y que estos matrimonios sean considerados legales en los mismos términos en que lo sería uno entre personas de sexo opuesto en todos los estados de la Unión ${ }^{18}$. En cuanto al asunto controvertido, la Corte ha limitado su revisión del caso a dos cuestiones centrales. La primera es si un matrimonio entre personas del mismo sexo debe ser previamente autorizado por los agentes civiles del estado en que ello se solicita. La segunda -y aquí está justamente la cuestión de James Obergefell- es si, al amparo de la Decimocuarta Enmienda, un matrimonio entre personas del mismo sexo es susceptible de reconocimiento por un estado que no contempla en su legislación civil ese derecho cuando el matrimonio ha sido autorizado y celebrado en otro que sí lo otorga.

Una primera parte del texto está dedicado casi íntegramente a reflexionar sobre la importancia del matrimonio como instituto social, pues aquí radica el punto de partida de los casos que se tratan en el fallo. Varias expresiones del juez Kennedy sobresalen aquí: la "dinámica [del matrimonio] permite a dos personas hallar una vida que no encontrarían solos. Desde nuestras más básicas necesidades humanas, el matrimonio es esencial para nuestras más profundas esperanzas y aspiraciones"19; agregando que "[Por el contrario] es la perdurable importancia del matrimonio lo que subyace a los argumentos de los peticionarios" 20 . No obstante el enaltecimiento que presta a la institución del matrimonio, Kennedy no se queda atrapado en sus orígenes. Muy por el contrario, el juez redactor reconoce que "la historia del matrimonio es una historia tanto de continuidad como de cambio (...) ha evolucionado a través del tiempo" 21 . Todo ello ha operado importantes cambios estructurales en el vínculo "afectando aspectos del matrimonio que han sido largamente considerados esenciales"22.

mócrata. No así en los de los jueces disidentes, que han sido nombrados por presidentes republicanos, en especial del clan Bush.

18 Supreme Court of Justice, 576 U.S._ (2015), 26 de junio de 2015.

19 Supreme Court of Justice, 576 U.S._ (2015), 26 de junio de 2015.

20 Supreme Court of Justice, 576 U.S._ (2015), 26 de junio de 2015.

21 Supreme Court of Justice, 576 U.S._ (2015), 26 de junio de 2015.

22 Supreme Court of Justice, 576 U.S._ (2015), 26 de junio de 2015. 
Similar atención presta Kennedy a la evolución, tanto en la jurisprudencia como en la misma sociedad, a la consideración debida a las personas homosexuales. Mientras que hasta mediados del siglo XX las naciones occidentales habían condenado la homosexualidad en varios campos jurídicos, la segunda mitad del siglo conoció importantes avances al respecto. No obstante, siguió habiendo restricciones significativas al ejercicio de los derechos de personas homosexuales. La expresión más significativa de aquello es el castigo penal asociado a la sodomía (que en Chile solo se abolió en la década del noventa ${ }^{23}$ ), pero en muchas otros campos de la vida civil, en muchos países occidentales la homosexualidad continuó y continúa constituyendo un factor de discriminación y menosprecio, así como de construcción de subjetividades marginalizadas y fuera de norma.

En general la no adecuación a los roles y estándares aceptados y validados en torno a lo masculino, ha sido desde antaño un argumento no expresado y a veces violentamente impuesto para condenar y estigmatizar toda forma de diferencia sexual, que excede la sola condición homosexual ${ }^{24}$. En ese sentido el occidente judeo-cristiano ha cimentado un sistema de relaciones de género heteronormado, en donde las desviaciones de la norma han sido sistemáticamente sancionadas en distintos ámbitos, y por supuesto en el jurídico. Michel Foucault reconoce que "A través de tantos discursos se multiplicaron las condenas judiciales por pequeñas perversiones; se anexó la irregularidad sexual a la enfermedad mental; se definió una norma de desarrollo de la sexualidad desde la infancia hasta la vejez y se caracterizó con cuidado todos los posibles desvíos (...) los médicos reunieron alrededor de las menores fantasías todo el enfático vocabulario de la abominación" 25 .

Esto alejó durante mucho tiempo la posibilidad de reconocer la homosexualidad como una práctica legítima dentro de la intimidad humana. Por el contrario, se preocupó de mantenerlas al margen, produciendo complejos procesos de construcción de subjetividades dobles, una oculta y otra pública.

23 Ello mediante la Ley No 19.617 de 12 de julio 1999 que, entre otras reformas, reemplazó el artículo 365 del Código Penal.

${ }^{24}$ En ese sentido reflexiona Eribon cuando indica que "el espacio público es heterosexual y los homosexuales son relegados al espacio de su vida privada. Se puede observar, por ejemplo, que todas las formas de la sociabilidad masculina (...) descansan igualmente en la exclusión de la homosexualidad”. ERIBON (2001), p. 144.

25 Foucault (2005), p. 37. 
Pese a ello, dichas prácticas siguieron existiendo y manifestándose en contextos de disimulación. En ese contexto de clandestinidad se produce lo que Foucault llama "una dispersión de sexualidades (...) Nuestra época ha sido iniciadora de las heterogeneidades sexuales" 26 . Como se verá, los argumentos de Obergefell evidencian una visibilización sustantiva que barre con los límites que el Derecho imponía entre dos realidades existentes, pero separadas por las consideraciones de legítimo/ilegítimo, normal/anormal que han gobernado la normatividad heterosexual. Se supera así, en parte, una subalteridad construida a partir del acceso denegado a determinadas instancias de publicidad de la vida privada, como es el matrimonio ${ }^{27}$.

A nivel jurídico es la imputación penal de las personas que incurren en prácticas sexuales con el mismo sexo lo que más llama la atención por su violencia. Pero desde la disciplina psiquiátrica hay que recordar que solo en 1973 la Asociación Americana de Psiquiatría decidió dejar de considerar la homosexualidad como un trastorno mental y en consecuencia la retiró del index de enfermedades a $\operatorname{tratar}^{28}$. El avance hacia la litigación, que concluiría en Obergefell, se hace posible justamente por un cambio en las percepciones sociales hacia la homosexualidad, gatilladas a su vez por desarrollos culturales y, sobre todo, políticos que han posibilitado dichos cambios.

En este contexto, la batalla por el reconocimiento puede tener varios escenarios distintos. No se debe perder de vista que la sociabilidad gay ha tenido como telón de fondo las grandes ciudades donde los homosexuales podían desarrollar

26 Foucault (2005), p. 38

27 Didier Eribon dedica algunas líneas (pocas) de su trabajo al tema del matrimonio igualitario, indicando que "El matrimonio realiza así una doble separación: la primera, la más visible, entre los que están casados y los que no lo están, y la segunda (...) entre los que tienen derecho a casarse y los que no tienen reconocido ese derecho". La institución del matrimonio establece así lo que el autor llama una "instauración performativa de la exclusión". ERIBON (2001), p. 163.

28 La American Psychiatry Association decidió, en su reunión de diciembre de 1973, emitir una declaración en la que afirmaba, entre otras cosas, que la homosexualidad per se no constituía ningún impedimento en el juicio, estabilidad, capacidades sociales o capacidades vocacionales. En consecuencia la Asociación resolvió rechazar la discriminación en contra de los homosexuales en una serie de ámbitos. Esto implicó la remoción de la homosexualidad del catálogo de patologías mentales que la Asociación elabora, y que se conoce por las siglas DMS (Diagnostic and Statistical Manual of Mental Disorders), en esos años en su segunda versión -la primera es de 1952 y en ella sí se consideraba a la homosexualidad una enfermedad-. Dicha posición se consignó en la revista oficial de la Asociación y fue preparada por el Dr. Robert Spitzer. Cabe señalar que, a lo largo de los años, esta posición de la Asociación ha sido reiterada en varias oportunidades a través de sus órganos. SPITZER (1974), p. 497. 
libremente una serie de instancias de socialización, con distintos grados de movimiento en el eje público-privado. Estas se caracterizan generalmente por tener lugar precisamente fuera de la familia de origen y muchas veces a contrapelo de la misma y en la cual los lazos de amistad fraterna y solidaridad cobran una importancia definitoria de una forma de vida ${ }^{29}$. El escenario más ruidoso es aquel en que los gais pugnan por que se les reconozcan espacios en términos de igualdad, dentro de instituciones cerradamente heterosexuales. Una de ellas es indudablemente el matrimonio; la otra es la adopción de hijos. Para Eribon, "la reivindicación del matrimonio gay no expresa solamente la aspiración (...) de determinados homosexuales a entrar en la institución matrimonial; aportaría asimismo (...) un profundo trastorno de la propia institución, que ya no podría ser la misma que antes (...) La desacralización del matrimonio posibilita la reivindicación en términos de abrir la institución a las parejas del mismo sexo"30.

Puede considerarse que hasta aquí los jueces de mayoría se hacen cargo de nuevas realidades sociales y las incorporan en el proceso de interpretación, concretando un contenido no expresamente resuelto en el texto, superando su carácter pétreo y asumiendo su mutabilidad como justificación de un cambio interpretativo. Tales realidades no son tan nuevas como se podría pensar, sino que han existido siempre en la invisibilidad. De manera que hay en Obergefell un reconocimiento y una puesta en valor de la vida que las personas homosexuales puedan llevar en tanto parejas y del estatus que éstas deben tener en el sistema legal, que no es sino reflejo de discursos que, desde lo político, lo psiquiátrico, lo jurídico, han usado el lenguaje de la injuria como principal instrumento de inferiorización ${ }^{31}$.

Así, en lo que a la interpretación respecta, hay aquí un interesante ejercicio hermenéutico que evidencia un viejo debate del constitucionalismo entre lo que se ha dado en llamar una línea originalista (representada en gran medida en las opiniones del fallecido Antonin Scalia) y la línea que se podría denominar progresista $^{32}$. La primera pugna principalmente por establecer cuál es la voluntad

\footnotetext{
29 ERibon (2001), p. 57.

30 ERIBON (2001), p. 62.

31 ERIBOn (2001).

32 Un debate similar se produce en Chile, en donde la doctrina ha mostrado una crítica al significativo rol que representa el método de interpretación originalista de la Constitución, que acude permanentemente a las actas de la Comisión Ortúzar, redactora del anteproyecto de Constitución. En ese sentido Bassa y Viera afirman acertadamente que "el originalismo conlleva el riesgo de petrificación y rigidización del derecho,
} 
subjetiva de los redactores de la Constitución para desde ahí juzgar la adecuación de las normas actuales a la Carta Fundamental. El debate se resuelve aquí en una clara noción de lo que debe ser una interpretación extensiva de la Carta que despliega una función creadora de nuevos derechos. En ese sentido, Obergefell resulta tributario de una línea interpretativa extensiva que supera la visión originalista en cuanto al establecimiento de nuevos derechos al señalar que "Las generaciones que redactaron y ratificaron la Carta de Derechos y la Decimocuarta Enmienda no pretendieron conocer la total extensión de la libertad, y por tanto confiaron a las futuras generaciones la misión de proteger el disfrute de todas las personas de esas libertades mientras vamos conociendo su significado"33.

\section{LOS FUNDAMENTOS CONSTITUCIONALES DEL MATRIMONIO IGUALITARIO}

\subsection{Obergefell: ¿un nuevo derecho?}

Una de las cuestiones más interesantes que plantea la decisión Obergefell es si se constituye un nuevo derecho al matrimonio a partir de ella o si se trata más bien del reconocimiento de un derecho ya existente ${ }^{34}$. Este problema es una vieja cuestión en el constitucionalismo norteamericano que ha sido tratada en la jurisprudencia constitucional con disímiles resultados. El pilar fundamental de esta discusión es la Novena Enmienda, que asume ya en el año 1791 que la enumeración de derechos en la Constitución no es taxativa, por lo cual nuevos derechos pueden ser creados en el futuro ${ }^{35}$. Hay a este respecto una clara línea de tensión en el desarrollo de la jurisprudencia. Por una parte, la Corte se ha encargado en el curso de los años de crear una larga lista de derechos que efectivamente no fueron considerados en el origen de la Constitución. La línea originalista de interpretación se ha quebrado en numerosas ocasiones, con mayorías muy estrechas, para favorecer una interpretación extensiva de la Constitución y,

además de no considerar el carácter evolutivo de los sistemas jurídicos, en tanto que manifestaciones culturales". Bassa y Viera (2008), p. 133.

33 Supreme Court of Justice, 576 U.S._ (2015), 26 de junio de 2015.

34 Como la misma sentencia señala, los peticionarios "no buscan ejercer un derecho a casarse sino un nuevo e inexistente derecho al matrimonio entre personas del mismo sexo" Supreme Court of Justice, 576 U.S._ (2015), 26 de junio de 2015.

35 El tenor literal es el siguiente: "La enumeración en la Constitución de determinados derechos no debe ser interpretada para denegar o menospreciar aquellos que retiene el pueblo" (traducción libre del autor de The Constitution of the United States). 
en ocasiones, derechamente innovadora y creativa. Pero por otro lado ha habido también un rechazo a la creación sin trabas de derechos no enumerados en el catálogo original. Para Yoshino, hay un terreno neutral donde la Corte ha elaborado dos aproximaciones opuestas a este problema ${ }^{36}$. La primera está representada por el voto de disenso redactado por el Juez de la Corte, John M. Harlan, en la decisión de Poe v. Ullman ${ }^{37}$ en 1961 y se trata de una visión proclive a crear jurisprudencialmente derechos no previamente existentes amparándolos en garantía del debido proceso, contenida en la Decimocuarta Enmienda. Para Yoshino, se expresa aquí una medida de razonabilidad que balancea las libertades individuales y los intereses del gobierno, pero donde la tradición no debe constituir una atadura al pasado que imponga construcciones formularias a los derechos. La posición contraria la representa la decisión Washington v. Glucksberg 38 de 1997, que sí contiene una posición formulista en cuanto al establecimiento de nuevos derechos bajo la garantía del debido proceso. Esta posición se caracteriza por establecer varios requisitos para que un derecho sea reconocido bajo la Decimocuarta Enmienda: Debe estar enraizado en la historia y tradición de la nación, implícito en el concepto de libertad, además de cuidadosamente descrito ${ }^{39}$.

¿Dónde es posible situar a Obergefell en este esquema? Obergefell viene en sustancia a crear un nuevo derecho que no existía con anterioridad en la Constitución y lo hace usando la puerta ancha que le brinda la Novena Enmienda. En tal sentido, Yoshino sostiene que el fallo de Obergefell es mucho más cercano a

\footnotetext{
36 Yoshino (2015), p. 149.

37 Poe v. Ullman es una sentencia dictada en 1961 en donde se discutió la constitucionalidad de los estatutos del estado de Connecticut que prohibían el uso de contraceptivos, otro de los grandes temas de derechos civiles en EE.UU. La sentencia concluyó que dichos estatutos eran constitucionales, con el disenso de Harlan.

38 En Washington v. Glucksberg (1997) ocho personas, entre ellas tres enfermos terminales, entablaron un litigio en contra de estatutos del estado de Washington que prohibía el suicidio asistido, considerado éste como una libertad amparada bajo la Decimocuarta Enmienda. La decisión del caso, por unanimidad, fue rechazar la posición de los peticionarios, bajo el argumento de que el derecho a una muerte asistida no quedaba amparado en la Decimocuarta Enmienda, pues no se trata de un derecho enraizado en la historia de la nación.

39 El autor explica cómo el recurso a la tradición y la historia ya había aparecido en 1986 en Bowers v. Hardwick, donde se discutía si el derecho a mantener relaciones homosexuales estaba garantizado. Según el autor decidir si tal derecho tenía sus raíces en la tradición o estaba implícito en el concepto de libertad era, en el mejor de los casos, jocoso. Lo novedoso es que, mientras en Bowers se mantenía la separación entre los requisitos, en Glucksberg los requisitos se transformaron en copulativos, con el consecuente estrechamiento del criterio para interpretar la Carta de Derechos creativamente. Yoshino (2015), p. 152.
} 
la línea creada por el disenso del juez Harlan en Poe v. Ullman que a Washington $v$. Glucksberg, pero no lo es del todo ${ }^{40}$. Ello en gran medida porque viene a romper con los tres requisitos que se habían formulado en 1997 para el reconocimiento de un nuevo derecho ${ }^{41}$. No obstante, y como han concordado algunos críticos de la decisión, Obergefell sí admite un fundamento en la tradición, sólo que con un matiz: si bien no es el matrimonio entre personas del mismo sexo un derecho que goce de larga tradición, ni esté enraizado en la historia de los EE.UU., para la opinión mayoritaria sí lo ha sido el matrimonio mismo. Desde este punto de vista, Obergefell no es propiamente un abandono de la tradición, sino más bien la ratificación de ésta bajo una nueva luz. Quizás una de las más importantes construcciones que realiza la sentencia es justamente reafirmar el derecho al matrimonio haciendo abstracción de quienes son los contrayentes, preguntándose para ello si existe suficiente justificación para excluir a las personas del mismo sexo.

\subsection{Obergefell y la Decimocuarta Enmienda}

Como ya se ha señalado, el fundamento de Obergefell recorre una extensión bien determinada de la Decimocuarta Enmienda a la Constitución. Esta cláusula, que data de mediados del siglo XIX, contiene una garantía de no privación de ninguna persona de su vida, su libertad o su propiedad, sin un debido proceso. Además, como una extensión de la garantía, se contempla seguidamente el derecho de no denegación de la igual protección de los derechos a ninguna persona bajo el imperio de la Constitución.

La redacción de esta garantía constitucional integra la llamada Carta de Derechos e indica una descomposición en dos partes: el debido proceso y la igual protección ante la ley. Los sentenciadores de mayoría en Obergefell han optado por sustentar el fallo en ambas partes, construyendo una lectura integral de la enmienda. Esta decisión, como se verá, ha sido objeto de variadas críticas, tanto por las consecuencias interpretativas como por las implicancias de fondo

\footnotetext{
40 Yoshino (2015), pp. 149, 162.

41 Los votos de disenso en Obergefell son claves para comprender que es lo que la decisión representa en términos de abandono de la idea de la tradición como requisito de reconocimiento. Dichos votos descansan en gran medida en considerar que el matrimonio entre personas del mismo sexo no goza de un anclaje en la tradición ni en la historia y mal podrían ser reconocidos como amparados en la Decimocuarta Enmienda.
} 
en cuanto a la consideración del matrimonio como centro de la vida social. No obstante, la línea jurisprudencial que sigue Obergefell es clara y ya venía siendo anunciada en pronunciamientos anteriores.

Así, Obergefell resulta coherente con la idea de des-formularizar el establecimiento de nuevos derechos al amparo de la constitución. No obstante, no es menos cierto que el juez Kennedy, luego de destacar cómo el derecho al matrimonio ya había sido objeto de protección constitucional con anterioridad, desarrolla los argumentos de mayoría recurriendo a conceptos que son más propios de Washington v. Glucksberg: La historia y la tradición y las demás libertades que van unidas al matrimonio. El fallo se descompone en esta parte en cuatro premisas que llevan a concluir que las parejas del mismo sexo pueden ejercer el derecho a casarse.

La primera considera al matrimonio como inherente al concepto de autonomía individual, al considerarlo entre las más íntimas decisiones que un individuo puede realizar ${ }^{42}$. El matrimonio permite el encuentro de otras libertades, independientemente de la orientación sexual de la persona. El concepto clave es el de libertad y autonomía decisional.

La segunda premisa considera que el matrimonio apoya la unión de dos personas y su compromiso mutuo en una forma en que ninguna otra institución hace. Por esta razón la jurisprudencia ha invalidado anteriormente otras prohibiciones, por ejemplo, que personas privadas de libertad contraigan matrimonio: "el derecho al matrimonio dignifica a las personas que desean definirse a sí mismos por su compromiso con el otro" 43 .

La tercera radica en el efecto de salvaguarda que el matrimonio proporciona a hijos y familias y los derechos relacionados con unos y otros. En ese sentido, el matrimonio provee un estatuto protector que excede a los contrayentes. Dado que en muchos estados de la Unión ya se ha reconocido previamente el derecho de las parejas del mismo sexo a criar hijos propios de uno de los integrantes o adoptados, resulta evidente que el paso siguiente es el reconocimiento constitucional de una estructura legal dentro de la cual tiene lugar, de manera preeminente, la crianza y educación de tales hijos. El no reconocimiento produciría un efecto de estigmatización de hijos de padres no casados, al no contar con el estatuto

42 Supreme Court of Justice, 576 U.S._ (2015), 26 de junio de 2015.

43 Supreme Court of Justice, 576 U.S._ (2015), 26 de junio de 2015. 
protector del matrimonio. Como se verá en el punto siguiente, esto será materia de duras críticas a la sentencia.

En cuarto y último lugar, evocando a Alexis de Tocqueville y remitiendo a antiguas decisiones, la Corte considera el matrimonio como una piedra angular del orden social, condición de civilización y progreso. Asimismo, se ha considerado el matrimonio como la base a partir de la cual pueden adquirirse otros beneficios sociales relacionados con propiedad, principalmente de vivienda social, pero también en relación con la herencia y las exenciones tributarias: En suma, se trata de "una constelación de beneficios que los estados han vinculado al matrimonio" 44 .

Ahora bien, ¿cuál es el argumento para no excluir a las parejas del mismo sexo de la protección que brinda el matrimonio? Justamente es en este punto donde la Corte se aleja más radicalmente de Washington v. Glucksberg que, como ya se veía, exigía que los nuevos derechos que se establecieran cumplieran con requisitos, como una cuidada o detallada descripción y una práctica histórica que lo avale. La Corte de Obergefell ha considerado que esta aproximación resulta inadecuada cuando se trata de un derecho -al matrimonio- que ya ha sido objeto de varias decisiones previas en las que la cuestión tratada no ha sido la existencia de un derecho a contraer matrimonio, sino si existe suficiente justificación para excluir a determinadas categorías de personas de ese derecho. Dado que las personas del mismo sexo persiguen que se les brinde el mismo trato que bajo la misma Constitución se les brinda a las personas de sexo opuesto, no es posible negar ese derecho sin menospreciar a los primeros.

En este orden de argumentos, queda por determinar cuál ha sido en realidad el anclaje constitucional que los jueces han dado a su decisión. Por de pronto, se ha despejado que la Decimocuarta Enmienda resulta un fundamento claro. No obstante, no es ocioso determinar a ciencia cierta en qué parte de una garantía que, como se ha visto, es doble, se sustenta la decisión.

Hasta ahora, se ha visto un fuerte componente de garantía de igual protección de la ley. Los jueces han estimado fuera de ley el no otorgar a parejas del mismo sexo la misma consideración que se les da a las de distinto sexo en cuanto al derecho a contraer matrimonio. La cláusula del debido proceso -nadie puede ser privado de derechos sin un debido proceso legal- parece estar un poco más alejada del argumento central. En Obergefell, el matrimonio es una institución en

44 Supreme Court of Justice, 576 U.S._ (2015), 26 de junio de 2015. 
evolución, su centralidad en el constructo social merece que les sean granjeados sus beneficios a todos quienes quieran adoptarlo como forma de compromiso vital y no hay motivo para considerar como distintas $-\mathrm{y}$ no extender por tanto los beneficios que implica- a las personas del mismo sexo. Solo el argumento de la realización de una libertad a través del matrimonio parece ser hasta aquí más cercano a la garantía del debido proceso.

En este punto la Corte de Obergefell discurre usando un interesante sincretismo entre las dos garantías que componen la Decimocuarta Enmienda ${ }^{45}$. Si bien los derechos que derivan de cada garantía pueden descansar en preceptos distintos que no siempre alcanzan la misma extensión pueden, en muchos casos, servir para determinar tanto el significado como el alcance de uno u otro. Se produce de esta forma una sinergia entre ambas garantías: La negación de un derecho que se debe reconocer a las distintas categorías de personas (identificados como tales por orientación sexual, raza o cualesquiera otras) produce una privación de libertades. Este argumento, usado para considerar inconstitucionales los estatutos que prohibían matrimonios entre personas de distintas razas -Loving $v$. Virginia-funciona de igual manera en Obergefell. El resultado es la cohesión de ambas garantías de modo funcional: la consideración de ser un estatuto contrario a la garantía de la igual protección ante la ley lleva a considerarlo asimismo como atentatorio contra el ejercicio de una libertad de la cual no puede una persona ser privada sin un debido proceso.

\subsection{Dos frentes criticos de Obergefell: el social y el constitucional-interpretativo}

Si bien se ha sostenido que Obergefell es la culminación de un largo proceso de litigación sobre el matrimonio igualitario, es indudable que su impacto no solo es jurídico, sino que debe leerse como el fin de una larga batalla que los y las homosexuales -y muchos heterosexuales- han librado para que se les equipare a las personas de sexo opuesto. Lo primero que puede destacarse de Obergefell

\footnotetext{
45 En ese mismo sentido señala Ethan Leib que "pese a que una decisión basada solo en la cláusula de la igual protección era posible, la decisión que el Juez Kennedy en realidad redactó es una mixtura de un discurso de igualdad, amparado en la jurisprudencia sobre la igual protección ante la ley y uno basado en los derechos fundamentales y basado en la cláusula del debido proceso”. LeIв (2015), p. 43.
} 
es precisamente el enorme aprecio que manifiesta a lo largo de sus páginas por la institución del matrimonio ${ }^{46}$.

Así como Obergefell ha sido esperado y celebrado en muchas latitudes, no es menos cierto que ha despertado críticas relevantes. Se explorarán en lo sucesivo algunas de ellas, tanto en el frente constitucional-argumentativo, como en el frente social.

Una de las críticas más relevantes proviene del frente de quienes sostienen que Obergefell supone una consolidación del matrimonio como única formulación posible de la familia, en desmedro de muchas familias que quedan fuera de cualquier rango de protección legal al no constituirse alrededor de este. En ese sentido, en un ensayo publicado tres meses antes de la decisión de Obergefell, Deborah Widdis argumentaba que la decisión en Windsor (antecedente directo de Obergefell) "implícitamente resucita y refuerza los alegatos en torno a que la crianza de hijos no matrimoniales -y en general las relaciones sexuales fuera del matrimonio- son inherentemente menos merecedoras de respeto que las matrimoniales" 47 . Pese a que la autora dirige sus dardos contra el fallo de 2013, las críticas también pueden aplicarse razonablemente a la sentencia que aquí se comenta.

Obergefell y sus argumentos descansan en una realidad que ha sido socialmente visibilizada de manera extensa y eficiente en los últimos años. El retrato social de la homosexualidad que ha sido largamente construido sobre la base de prejuicios, acusaciones, etiquetas medicalizantes e invisivilización ha renovado sus formas en los últimos años de una manera bastante acelerada, de la mano de una legitimación ganada a pulso y en la cual el frente judicial ha sido más bien un corolario natural. Clases progresistas, principalmente urbanas, han abrazado la llamada causa gay por motivos que quizás obedecen más a la exacerbación del valor de la libertad que al de la igualdad. Se podría pensar aquí que lo importante son los resultados a que ha sido empujado el problema, pero no debe perderse de vista que los homosexuales son una pequeña proporción de la población en términos demográficos, que muchos niños nacen de mujeres no

\footnotetext{
46 Lo atestiguan las líneas del juez Kennedy: "No hay unión más profunda que el matrimonio, pues ésta encarna los más altos ideales del amor, fidelidad, devoción, sacrificio y familia. En la formación de una unión marital dos personas se convierten en algo más grande de lo que eran. (...) Sería un mal entender a estos hombres y mujeres el considerar que estos no respetan la idea del matrimonio". Supreme Court of Justice, 576 U.S._ (2015), 26 de junio de 2015.
}

47 WidDis (2015), p. 549. 
casadas y que muchas familias hetero u homosexuales se conforman al margen de la formalidad matrimonial. Widdis señala, acertadamente, que "el matrimonio de larga duración es común solo entre un sector de la población relativamente acomodado, altamente educado y desproporcionadamente blanco"48-49-50.

Bajo esta línea crítica, decisiones del orden de Windsor y de Obergefell se centran en extremar sus consideraciones respecto al matrimonio como la más perfecta unión entre personas. Es comprensible que ello sea necesario para atender de forma racional y justificada las pretensiones de los peticionarios. Pero no se debe perder de vista que cada vez existe una mayor necesidad de reconocer configuraciones familiares no matrimoniales y que son igualmente demandantes de protección por parte de los estados. La superioridad del matrimonio como forma familiar implica un denso complejo de deberes y normas que trascienden lo jurídico, pero sobre todo una normatividad sexual que funciona dentro de sus límites de licitud y fuera de la cual todo es ilícito ${ }^{51}$. Si la moral sexual se centraba principalmente en el matrimonio y se preocupaba de normarlo hasta en sus menores detalles, la actualidad parece haber abandonado en algún grado la regulación de las prácticas sexuales al interior del matrimonio para concentrarse en una larga serie de efectos asociados al mismo: sucesión de bienes, deberes de alimentos y asistencia, filiaciones presuntas, derechos y obligaciones para con los hijos comunes, regímenes patrimoniales, régimen de término, reparaciones o compensaciones posmatrimoniales. La larga lista de regulaciones que rodean al matrimonio hace parecer un juego de niños las normatividades a que refiere Foucault. Fuera de ese campo reglado, una cada vez mayor proporción de personas deciden construir familias y relaciones de afecto no matrimoniales, pero que de un modo u otro precisan ser reconocidas como tales ante el esta-

48 Widdis (2015), p. 550.

49 Algo similar puede decirse de nuestra realidad nacional. El Instituto Nacional de Estadísticas registra que de los casi 65.000 matrimonios que se celebraron en Chile en 2014, en algo más de 56.000 de ellos la contrayente mujer tenía más de 10 años de estudios. Instituto Nacional de Estadísticas (2014), p. 170.

50 No obstante Gates y Brown documentan un aumento en la proporción de parejas del mismo sexo que se casaron tras las decisiones de Windsor y Obergefell, los datos no efectúan una segregación por clase social. GATES Y BROWN (2015).

51 En ese sentido Foucault indica en su Historia de la Sexualidad que "Hasta fines del siglo XVIII, tres grandes códigos explícitos (...) regían las prácticas sexuales: derecho canónico, pastoral cristiana y ley civil. Fijaban (...) la línea divisoria de lo lícito y lo ilícito. Pero todos estaban centrados en las relaciones matrimoniales: el deber conyugal, la capacidad para cumplirlo, la manera de observarlo..." FOUCAULT (2005), p. 38. 
do. Para Widiss, las tendencias demográficas sugieren que "si las políticas del gobierno continúan dependiendo exclusiva o primariamente del matrimonio como indicador de interdependencia familiar, esas políticas dejarán fuera a una significativa proporción de los más pobres y vulnerables parejas del mismo sexo y a sus hijos" $52-53$. Las variables clase, género y raza parecen superponerse a la de orientación sexual.

En un mismo sentido se pronuncia Huntington al señalar derechamente que la decisión de Obergefell "no respeta a las personas que, de buena fe, mantienen una distinta visión sobre el matrimonio. Y materializa a éste como un elemento clave en el frontis social de la familia, marginalizando en consecuencia a las familias no matrimoniales" 54 . Esto explica en definitiva que Obergefell ha representado una lucha no solo por la inclusión, sino también por el control del significado del matrimonio y de los arquetipos que socialmente se construyen en torno a éste. Así los sostenedores de la causa del matrimonio igualitario no han empujado un cambio, sino que solo han reclamado -legítimamente, por cierto- acceso a él. Pero en lo demás han sido tributarios de todas las consideraciones que han levantado el matrimonio a la máxima expresión de vida en pareja y pieza clave del orden social.

Con todo, este argumento no solo resulta relevante en la crítica de las consecuencias en el frente social de la sentencia como la se comenta aquí. Para Huntington ello va unido al desarrollo interpretativo de la Corte. La opción del juez Kennedy por fundamentar la decisión en la garantía del debido proceso ha obligado a indagar en la historia y el papel del matrimonio dentro de la sociedad para, desde ahí, realzarlo de modo de elevarlo a una categoría superior. Para la autora la decisión debió haberse basado solo en la cláusula de la garantía de igual protección, pues así "la Corte habría concluido que, independientemente del significado social del matrimonio, los estados no pueden denegar acceso a éste basado en la orientación sexual”55. Esto permite calificar a Obergefell como una

\footnotetext{
52 Widiss (2015), p. 570.

53 Leib sintetiza una interesante propuesta que tiene por objeto desmatrimonializar el orden familiar. Algunas estrategias podrían ser las uniones civiles únicas, como único arreglo disponible por parte del estado federal, enriquecer el pool de opciones estatales para la vida familiar sin privilegiar ninguna de ellas por sobre otras o (en un plano más radical) repensar el derecho de familia de forma de que en un futuro el estado se aleje del dormitorio y el hogar. Lеiв (2015), p. 47.

54 Huntington (2015), p. 23.

55 Huntington (2015), p. 27.
} 
decisión curiosamente conservadora pues opta por una línea de argumentación constitucional que, forzadamente, hace a la Corte entrar en el terreno de definir y en consecuencia optar por una forma de familia basada en el matrimonio.

\section{EL CASO CHILENO: ANTECEDENTES PARA LA DISCUSIÓN}

No es de extrañar, por lo tanto, que el matrimonio igualitario se haya transformado en un objetivo político de la comunidad gay a nivel global que ha obtenido un éxito significativo en la "primera democracia" del mundo ${ }^{56}$. Y tampoco lo es que, a partir de esa lucha se hayan seguido importantes cuestionamientos a la institución misma del matrimonio como base de la familia y que los homosexuales, en cuanto sujeto político, busquen acceso a una institución marcadamente heterosexual.

La tendencia permite proyectar que prontamente Chile entrará en una fase de debate parlamentario sobre el matrimonio entre personas del mismo sexo, pues se trata de procesos cada vez más acelerados ${ }^{57}$. El estado actual de la cuestión está atravesado por varias cuestiones e hitos relevantes. Surge, en primer lugar, el fantasma del fallo dictado contra Chile por la Corte Interamericana de Derechos Humanos en el caso llamado Atala Riffo y Niñas v. Chile ${ }^{58}$, que en 2012 ya impuso sanciones a Chile por haberse vulnerado el derecho a la vida privada de la recurrente al indagarse sobre su condición sexual en el análisis sobre su rol parental y haber conducido ello a una discriminación que implicó el retiro del cuidado personal de tres menores ${ }^{59}$. Pero la cuestión relativa a los derechos de

56 En su libro Global Gay, Frédéric Martel documenta extensamente el rol y el compromiso de la administración Obama en el apoyo a las comunidades y organizaciones gay en su lucha por el matrimonio igualitario. MARTEL (2013).

57 La administración Bachelet comprometió en 2016 el envío de un Proyecto de Ley al parlamento sobre matrimonio igualitario para la primera mitad de 2017. Fuente http:/www.emol.com/noticias/ Nacional/2016/09/21/823044/Presidenta-Bachelet-compromete-envio-de-proyecto-de-matrimonioigualitario-para-primer-semestre-de-2017.html (revisado 30 de enero de 2017). En efecto, con fecha 5 de septiembre de 2017 ingresó al Senado el Mensaje de la Presidenta de la República No 130-365, conteniendo el proyecto de ley que regula en igualdad de condiciones el matrimonio de las parejas del mismo sexo (Boletín No 11422-07).

58 Corte IDH, serie C No 254, de 21 de noviembre de 2012.

59 En 2016 se estrenó en Chile el film "Rara”, en que la directora Pepa San Martín ficciona sobre el caso de Karen Atala desde la mirada de Sara, una hija que entra en la adolescencia en el contexto de una familia homoparental. La película es un magnífico y sobrio ejercicio narrativo y actoral que pone el acento en la domesticidad de una familia y sus problemas cotidianos, bajo la sombra del conflicto paterno-materno. 
personas homosexuales se extiende a otros colectivos minoritarios y, sobre todo, a varias otras temáticas que superan con mucho la sola problemática del matrimonio. Así lo recuerda, por ejemplo, el Informe de Derechos Humanos 2015 de la Universidad Diego Portales, que en su capítulo dedicado a los Derechos de la Diversidad Sexual advierte falencias en materia de identidad de género, violencia contra personas LGBT y en educación en la diversidad sexual ${ }^{60}$. Pareciera en ese sentido que, pese al reconocimiento que se produce respecto de las personas homosexuales a partir de la Ley No 20.830 sobre Acuerdo de Unión Civil, el problema del matrimonio igualitario pasa a segundo plano, opacado por problemas que son sin duda anteriores y quizás más profundos que la discriminación en el acceso a esa forma de dar forma a la familia. Es posible y deseable que, una vez superado el problema del matrimonio igualitario, el debate entre en una nueva fase en que se profundice en el cuestionamiento de los roles de género, el gran tema que subyace a la consideración de los homosexuales como no merecedores de la misma consideración social y jurídica que se les dispensa a los heterosexuales. En tal sentido, un verdadero giro vendrá cuando lo que se ponga en cuestión no sea propiamente la institución matrimonial, sino los roles que a los sexos biológicos les son asignados dentro de la sociedad, subvirtiendo así los mecanismos de poder que avalan esos roles ${ }^{61}$.

\section{Conclusiones}

1. No obstante las críticas que la doctrina ha dirigido en contra de la sentencia en Obergefell, su dictación ha significado un hito para las luchas por la igualación de personas a quienes se debe una consideración de iguales y a quienes, por lo

Una mirada similar, aunque en otro contexto y bajo otras problemáticas, se muestra en "The Kids are All Right", de Lisa Cholodenko (2010). Finalmente, en "Freeheld", dirigida en 2015 por Peter Sollet, Julianne Moore encarna a la oficial de policía gay Laurel Hester, quien murió de cáncer en 2006, no sin antes protagonizar una sentida batalla para que el Ocean County de New Jersey reconociera su derecho a dejar su pensión a su conviviente doméstica tras su muerte. Una premonición de lo que sería Obergefell varios años después.

60 Centro de Derechos Humanos, Facultad de Derecho de la Universidad Diego Portales (2015), pp. 365-385.

61 En ese sentido argumenta Butler, cuando afirma que "la repetición de construcciones heterosexuales dentro de las culturas sexuales gay y hetero bien puede ser el punto de partida inevitable de la desnaturalización y la desmovilización de las categorías de género; la reproducción de estas construcciones en marcos no heterosexuales pone de manifiesto el carácter completamente construido del supuesto original heterosexual”. ButLER (1999), p. 95. 
demás, ya se venía prestando dicha consideración a través de la mayoría de los estados de la Unión. Se trata de una decisión emancipadora que contribuye de forma significativa a la construcción de una sociedad más democrática. Asimismo es el cruce de una nueva frontera en el mundo de los derechos civiles. Sin embargo es necesario hacerse cargo de que Obergefell expone un razonamiento en que, para llegar a la conclusión de que no puede darse un trato desigual, eleva el matrimonio a la máxima expresión de la vida en pareja. Sus consecuencias pueden ser importantes para la consideración que se debe a una amplísima parte de la población que, independientemente de su orientación sexual, forma relaciones afectivas y construye familia al margen de la institución del matrimonio.

2. Con todo, Obergefell posee el mérito de exhibir una argumentación que logra superar el carácter supuestamente pétreo de la Constitución Política, con una lectura que hace progresar su contenido de acuerdo a las nuevas consideraciones que la teoría social sobre el matrimonio avanza. Si bien el ejercicio interpretativo puede producir resquemores, no es menos cierto que a partir de la sentencia, las representaciones sociales de la homosexualidad y su derecho a acceder a instituciones hasta ahora cerradamente heterosexuales se equiparan a las exigencias de un estado democrático de derecho. La sentencia y sus argumentos son útiles para el debate a nivel nacional sobre el problema, sobre todo teniendo en cuenta que cualquier intento legislativo de re-definir igualitariamente el matrimonio será probablemente zanjado, en un sentido u otro, en el frente constitucional y ante el Tribunal Constitucional, tal como se hizo en los EE.UU.

3. No es posible desconocer que la deificación del matrimonio como forma de unión y fundamento de la familia, se basa en asignaciones de roles y una división sexual del trabajo de suyo antigua y en profunda crisis. La forma en que el derecho se hace cargo de aquello ha sido superada largamente por la realidad, y de ahí que las adecuaciones que se requieren no pasan solamente por proveer de un merecido estatuto de igualdad a los homosexuales, sino por asumir y fomentar aquello que tanto se teme desde el mundo conservador: una re-formulación de los roles de género que recién comienza tímidamente a avanzar entre ciertas clases progresistas. Es tiempo ya.

\section{Bibliografía CiTADA}

Bassa, Jaime; Viera, Christian (2008). "Contradicciones de los fundamentos teóricos de la Constitución chilena con el Estado constitucional-notas para 
su reinterpretación”, en Revista de Derecho, Vol. XXI (No 2-diciembre), pp. 131-150.

Blackman, Josh; Wasserman, Howard (2016). "The Process of Marriage Equality", en Florida International University, Legal Studies Research Paper Series (No 15), p. 33.

ButLER, Judith (1999). El género en disputa: El feminismo y la subversión de la identidad (Barcelona, Paidós).

Center for Disease Control and Prevention (2015). "National Vital Statistics Reports" [fecha de consulta: 11 de septiembre de 2016] [Disponible en http://www.cdc.gov/nchs/fastats/unmarried-childbearing.htm].

Corral, Hernán (2013). "Acuerdo de vida en pareja: ¿De la unión civil al matrimonio homosexual?”, en; Gómez de la Torre, Maricruz (Dir.) y Lepin, Christian (Coord.), Parejas homosexuales ¿Unión civil o matrimonial? (Santiago de Chile, Legal Publishing Chile), pp. 103-114.

Eribon, Didier (2001). Reflexiones sobre la cuestión gay (Barcelona, Anagrama). Foucault, Michel (2005). Historia de la sexualidad: 1. La voluntad de saber (Madrid, Siglo XXI).

Gates, G. J., Brown, T. N. T. (2015). "Marriage and Same-sex Couples after Obergefell”. (Los Angeles, CA, Williams Institute, UCLA School of Law), [fecha de consulta: 2 de febrero de 2017]. [Disponible en: https://williamsinstitute.law.ucla.edu/wp-content/uploads/Marriage-and-Same-sex-Couplesafter-Obergefell-November-2015.pdf].

Grossman, Cecilia y Herrera, Marisa (2013). “Tensiones y desafíos del derecho a contraer matrimonio de las parejas del mismo sexo. La experiencia en el Derecho argentino", en Gómez de la Torre, Maricruz (Dir.) y Lepin, Christian (Coord.), Parejas homosexuales ¿Unión civil o matrimonial? (Santiago de Chile, Legal Publishing Chile), pp. 137-176.

Hesse, Konrad (1992). Escritos de Derecho Constitucional (Madrid, Centro de Estudios Constitucionales).

Huntington, Clare (2015). "Obergefell's Conservatism: Reifying Familial Fronts”, en Fordham Law Review, Vol. 84, (No 1), pp. 23-31.

Instituto Nacional de Estadísticas (2014). Anuario de estadisticas vitales, 2014 (Santiago, INE).

LeIB, Ethan (2015). "Hail Marriage and Farewell”, en Fordham Law Review, Vol. 84, (No 1), pp. 41-52. 
Martel, Frédéric (2013). Global Gay: Cómo la revolución gay está cambiando el mundo (México, DF, Taurus).

Sedaris, David (2015). "A Modest Proposal", en The New Yorker, [fecha de consulta: 15 de diciembre de 2016]. [Disponible en: http://www.newyorker. com/magazine/2015/09/28/a-modest-proposal].

SpITZER, Robert (1974). "Position Statement on Homosexuality and Civil Rights", en American Journal of Psychiatry, Vol. 131 (No 4), p. 497.

Centro de Derechos Humanos, Facultad de Derecho de la Universidad Diego Portales (2015). "Informe Anual sobre Derechos Humanos en Chile, 2015”, [fecha de consulta: 15 de diciembre de 2016]. [Disponible en http://www.derechoshumanos.udp.cl/derechoshumanos/index.php/informeddhh-2015].

Yoshino, Kenji (2015). "A New Birth of Freedom?: Obergefell v. Hodges", en Harvard Law Review, Vol. 129, pp. 147-179.

Widdis, Deborah (2015). "Non - Marital Families and (or After?) Marriage Equality", en Florida State University Law Review, Vol. 42, pp. 547-572.

\section{JURISPRUDENCIA CITADA}

Obergefell et al. V. Hodges, Director, Ohio Department of Health et al. (2015). Supreme Court of Justice, 26 de junio de 2015, [fecha de consulta: 11 de octubre de 2016]. [Disponible en https://www.supremecourt.gov/ opinions/14pdf/14-556_3204.pdf].

Loving v. Virginia (1967). Supreme Court of Justice, 12 de junio de 1967, [fecha de consulta: 11 de octubre de 2016]. [Disponible en https://supreme.justia. $\mathrm{com} / \mathrm{cases} / \mathrm{federal} / \mathrm{us} / 388 / 1 / \mathrm{case} \cdot \mathrm{html} \# 4$ ].

Lawrence v. Texas (2003). Supreme Court of Justice, 26 de junio de 2003, [fecha de consulta: 11 de octubre de 2016]. [Disponible en https://www.law.cornell. edu/supct/html/02-102.ZS.html].

Windsor v. United States (2013). Supreme Court of Justice, 26 de junio de 2013, [11 de octubre de 2016]. [Disponible en https://www.supremecourt.gov/ opinions/12pdf/12-307_6j37.pdf].

Atala Riffo y niñas vs. Chile (2012). Corte IDH 21 de noviembre de 2012 (Solicitud de Interpretación de la Sentencia de Fondo, Reparaciones y Costas) Serie C No 254. 